\title{
Cost of achieving a balance in the anaesthetic department of a district general hospital
}

\author{
J Hurst, J A Curson
}

\begin{abstract}
In Achieving a Balance the Department of Health published requirements for medical staffing in hospitals. To review the effect that these would be likely to have a study was undertaken in the anaesthetic department of a district general hospital. The results were then validated with staffing levels in a new district general hospital with only one tier of junior staff.

It was found that over the next $\mathbf{1 0}$ years a massive expansion in the numbers of consultants would be needed at a cost of $£ 108000$ in salaries and employer's contributions alone.
\end{abstract}

\section{Introduction}

In Achieving a Balance $e^{1}$ the Department of Health and Social Security published the following requirements for medical staffing in hospitals: $(i)$ an increase in the number of consultants; (ii) sensible planning of numbers of doctors in training; and (iii) maintaining the necessary number of doctors to support consultants, particularly in the acute specialties.

North Bedfordshire Health Authority participated in a pilot study to investigate the possible effects of achieving a balance on medical staffing and the delivery of services in the North West Thames region. Although the effects on all "safety net" specialties were considered, only the work on anaesthetics is discussed here.

This hospital is a small district general hospital with 600 beds and serves a catchment population of 220000 . Existing numbers of staff in anaesthetics are below the national mean. ${ }^{2}$ There are no senior registrar posts and much reliance is placed on doctors with clinical assistant appointments of more than six sessions.

We attempted to predict how the anaesthetic department might be staffed in 10 years' time, assuming that the current level of service was maintained and the recommendations of Achieving $a$ Balance implemented.

\section{Method}

Indicative quotas of registrars supplied by the Joint

Bedford General Hospital, Bedford MK40 9DJ

J Hurst, FFARCS, consultant anaesthetist

$\mathrm{J}$ A Curson, MB, senior registrar in community

medicine

Correspondence to: $\mathrm{Dr} J \mathrm{~A}$ Curson, North Bedfordshire Health Authority, 3 Kimbolton Road, Bedford MK40 2NU. provide this service in 10 years' time based on the following assumptions. (1) The number of registrar posts would be reduced from four to one. (2) We would be unable to recruit visiting registrars. (Visiting registrars are overseas doctors who come to the United Kingdom for up to four years of postgraduate training. The inflow of overseas doctors is decreasing and the availability of visiting registrars in 10 years' time is impossible to estimate. None of our present registrars would be eligible for visiting posts.) (3) No clinical assistant posts of more than six sessions would be permitted. (4) We would not be allocated any of the limited staff doctor posts. (5) The remaining registrar and three senior house officers would work on the same on call rota, which would be one in four plus internal cover. (6) The Association of Anaesthetists' guidelines on consultant workload were used. ${ }^{34}$ (7) Arrangements for internal cover of leave would be required for all grades of staff. (This is not a requirement of Achieving a Balance, but the rising costs of hiring locums mean that locum cover will no longer be a viable option for this district.) (8) The notional half days allowed for consultants' on call commitments would be as follows: first on call, covering senior house officer, night four, weekend 12; first on call, covering registrar, night two, weekend six; second on call, night one, weekend three. (9) Half a session per consultant would be allowed for teaching and administration.

The staffing and workload were compared with those in the department of anaesthesia at Milton Keynes General Hospital to validate our theoretical calculations against the reality of staffing a department of anaesthesia without a middle tier. The additional costs of the new staffing levels were then calculated.

\section{Results}

Table I gives the existing staffing levels and the proposed initial changes under Achieving a Balance. An additional consultant would be required for the existing staffing levels to meet the Association of Anaesthetists' guidelines. ${ }^{3+}$

TABLE I-Staffing levels: existing and proposed levels as a consequence of achieving a balance

\begin{tabular}{lcc}
\hline \multicolumn{1}{c}{ Grade } & Existing & Proposed \\
\hline Consultant & $6 \cdot 5$ & $6 \cdot 5$ \\
Associate specialist & $1 \cdot 0$ & $1 \cdot 0$ \\
Registrar & $4 \cdot 0$ & $1 \cdot 0$ \\
Senior house officer & $3 \cdot 0$ & 3.0 \\
Clinical assistant & $2 \cdot 2$ & 0.6
\end{tabular}

Table II shows the existing workload and the notional half days of consultant time which would be required to do the work currently done by consultants, the three registrars who would be lost, and the clinical assistants with appointments of more than six sessions.

A total of 141.5 notional half days would be required (12.9 whole time equivalents). This surprising 


\begin{tabular}{|c|c|c|c|}
\hline Nature & $\begin{array}{l}\text { No of } \\
\text { sessions }\end{array}$ & Currently done by & $\begin{array}{l}\text { Notional half days } \\
\text { if done by consultant }\end{array}$ \\
\hline $\begin{array}{l}\text { Operating theatre lists plus } \\
\text { pre/postoperative assessment }\end{array}$ & $38 \cdot 5$ & Consultants & $64 \cdot 0$ \\
\hline $\begin{array}{l}\text { Operating theatre lists plus } \\
\text { pre/postoperative assessment }\end{array}$ & $8 \cdot 0$ & Junior doctors & \\
\hline Operating theatre lists & $10 \cdot 0$ & Associate specialist/clinical assistant & No change \\
\hline Intensive care sessions & $3 \cdot 0$ & Consultant \} & (8) \\
\hline Obstetric sessions & $2 \cdot 0$ & Consultant $\}$ & $3 \cdot 7$ \\
\hline Intensive care/obstetric cover & & Registrar/clinical assistant & $5 \cdot 7$ \\
\hline Teaching and administration & $0 \cdot 0$ & & 6.5 \\
\hline First consultant on call at night & & Registrar & $28 \cdot 0$ \\
\hline Second consultant on call at night & & Consultant & $8 \cdot 0$ \\
\hline Day time duty doctor & & Registrar & $11 \cdot 4$ \\
\hline $\mathbf{T}$ & & & 141.5 \\
\hline
\end{tabular}
registrars and 1.6 whole time equivalent clinical assistants was compared with the staffing at Milton Keynes Hospital. There, 10 consultants, one registrar, and four senior house officers deal with a workload $86 \%$ of that in this hospital (using the workload indicator adopted for the calculations made by North West Thames region).

In addition, to provide internal cover for annual leave and study leave a further $27 \cdot 0$ notional half days would be required. Thus a total of 15.3 consultants would be required, an additional 8.8 whole time equivalents. The total cost of these extra consultant staff would be $£ 296000$, although this would be offset by savings in the costs of registrars $(£ 66000)$ and locums ( $\$ 89000$ in 1987), leaving the total cost of achieving a balance at $£ 108000$. This figure assumes, perhaps unreasonably, that the 16 consultants would be prepared to share the present one secretary in anaesthetics.

\section{Discussion}

In Achieving a Balance it was proposed that the numbers of consultants should increase by $2 \%$ per year. In this study we calculated that to maintain the existing workload an expansion of $9 \%$ per year would be required. When we compared this hospital with Milton Keynes Hospital our findings were not as far fetched as they at first seemed. Our estimates of consultant staffing are $30 \%$ greater than those pertaining in Milton Keynes, while our workload is $20 \%$ greater.

For the health authority the cost of achieving a balance would be prohibitive. If all specialties in all districts implemented such an increase in consultant staff not only would the costs be phenomenal but there would not be sufficient numbers of trained doctors to fill the vacancies. The balance would again be lost.

We thank Dr M J Cowen, consultant anaesthetist, Milton Keynes Hospital, and the consultant anaesthetic staff of Bedford General Hospital.

1 Department of Health and Social Security. Hospital medical staffing - achieving a balance - a plan for action. London: HMSO, 1987.

2. Department of Health and Social Security. Performance indicators for the NHS. London: DHSS, 1988

3 Association of Anaesthetists of Great Britain and Ireland. Workload for consultants. London: Association of Anaesthetists, 1983.

4 Association of Anaesthetists of Great Britain and Ireland. Workload for consultant anaesthetists: implications of reductions in junior staff and the consultant-only hospital. London: Association of Anaesthetists, 1984.

(Accepted 19 fuly 1988)

\title{
Unusual presentation of pseudomonas infection
}

\author{
Michael J Weinbren, Gary Forgeson, Gilla Helenglass, Beryl Jameson, Ray Powles
}

Departments of Medicine and Microbiology, Royal Marsden Hospital and Institute of Cancer

Research, Sutton, Surrey Michael J Weinbren, MB, senior registrar, microbiology Gary Forgeson, FRACP, senior registrar in medical oncology

Gilla Helenglass, MRCP, honorary senior registrar, leukaemia unit

Beryl Jameson, FRCPATH, consultant microbiologist

Ray Powles, FRCP, consultant physician in charge, leukaemia unit

Correspondence to: $\mathrm{Dr}$ Michael J Weinbren, Department of Microbiology, Queen Mary's Hospital, Roehampton, London SW15 5PN.
Colonisation in the patient with neutropenia often heralds impending invasive pseudomonas infection ${ }^{\prime}$ which is associated with a high mortality. ${ }^{23} \mathrm{We}$ describe three cases of an uncommon presentation of pseudomonas infection consisting of extensive oropharyngeal ulceration and facial cellulitis with pronounced swelling of the face and associated septicaemia.

\section{Case reports}

Case 1-A 24 year old woman developed a low grade fever and mild oedema of the face after a relapse of acute myeloid leukaemia. Examination showed that the mucous membranes of the mouth were normal; bacteriological cultures of the mouth and oropharynx failed to grow any pathogens; and the peripheral white blood cell count was $1 \cdot 7 \times 10^{9} / 1$ with $90 \%$ myeloblasts. She was treated with gentamicin, metronidazole, cefuroxime, and erythromycin. As the peripheral myeloblast count was rising she was given tumour necrosis factor, an experimental biological response modifier. ${ }^{4}$ Gum lesions developed which were thought to be leukaemic infiltrates. She had a fever during which Pseudomonas aeruginosa was isolated from repeated blood cultures and a mouth swab. The antibiotics were continued and her fever settled within 48 hours. She received a further course of tumour necrosis factor, and 24 hours later had severe pain in the mouth and oropharynx and rapidly progressive oedema of the lower face and neck. Haemorrhagic necrosis was seen in the oral cavity, which was thought to be drug induced angio-oedema and she was treated with systemic corticosteroids and the same antibiotics. Her condition deteriorated, and she died within 12 hours. Necropsy showed tissue invasion with Gram negative bacilli compatible with pseudomonas (see figure).

Case 2-A 47 year old man who had a relapse of acute myeloid leukaemia and was undergoing reinduction chemotherapy developed severe bilateral oedema of the lower face and neck over 12 hours. $\mathrm{He}$ was neutropenic, with a white blood count of $0 \cdot 1 \times 10^{\circ} / 1$. He had had a temperature of $38^{\circ} \mathrm{C}$ to $40^{\circ} \mathrm{C}$ for the preceding six days and been treated with combinations of gentamicin, piperacillin, flucloxacillin, metronidazole, amphotericin B, and cefuroxime sequentially with no resolution of the fever. A strain of Pseudomonas aeruginosa resistant to piperacillin had been isolated from routine mouth swabs seven days before this. There were extensive areas of infected, necrotic tissue in the oral cavity affecting the hard palate and buccal mucosa. Pseudomonas aeruginosa sensitive to gentamicin, amikacin, and ciprofloxacin but resistant to piperacillin was isolated from blood cultures and repeat mouth swabs. Treatment was 